\title{
Comparative differential proteomic analysis of minimal change disease and focal segmental glomerulosclerosis
}

Vanessa Pérez ${ }^{1,2^{*}}$, Dolores López ${ }^{3}$, Ester Boixadera ${ }^{4}$, Meritxell Ibernón $^{2}$, Anna Espinall $^{4}$, Josep Bonet ${ }^{2}$ and Ramón Romero ${ }^{1,2,5}$

\begin{abstract}
Background: Minimal change disease (MCD) and primary focal segmental glomerulosclerosis (FSGS) are glomerular diseases characterized by nephrotic syndrome. Their diagnosis requires a renal biopsy, but it is an invasive procedure with potential complications. In a small biopsy sample, where only normal glomeruli are observed, FSGS cannot be differentiated from MCD. The correct diagnosis is crucial to an effective treatment, as MCD is normally responsive to steroid therapy, whereas FSGS is usually resistant.

The purpose of our study was to discover and validate novel early urinary biomarkers capable to differentiate between MCD and FSGS.

Methods: Forty-nine patients biopsy-diagnosed of MCD and primary FSGS were randomly subdivided into a training set (10 MCD, 11 FSGS) and a validation set (14 MCD, 14 FSGS). The urinary proteome of the training set was analyzed by two-dimensional differential gel electrophoresis coupled with mass spectrometry. The proteins identified were quantified by enzyme-linked immunosorbent assay in urine samples from the validation set.

Results: Urinary concentration of alpha-1 antitrypsin, transferrin, histatin-3 and 395 ribosomal protein L17 was decreased and calretinin was increased in FSGS compared to MCD. These proteins were used to build a decision tree capable to predict patient's pathology.

Conclusions: This preliminary study suggests a group of urinary proteins as possible non-invasive biomarkers with potential value in the differential diagnosis of MCD and FSGS. These biomarkers would reduce the number of misdiagnoses, avoiding unnecessary or inadequate treatments.
\end{abstract}

Keywords: Focal segmental glomerulosclerosis, Glomerular disease, Mass spectrometry, Minimal change disease, Proteomics, Urine, 2D-DIGE

\section{Background}

Minimal change disease (MCD) and primary focal segmental glomerulosclerosis (FSGS) are glomerular diseases defined by lesions of the podocyte. These diseases are main causes of idiopathic nephrotic syndrome in children and adults and are characterized by proteinuria,

\footnotetext{
*Correspondence: vperez.igtp@gmail.es; v.perezj@yahoo.es

'Laboratory of Experimental Nephrology, Institut d'Investigació en Ciències de la Salut Germans Trias i Pujol, Universitat Autònoma de Barcelona, Badalona, Spain

2Department of Nephrology, Hospital Universitari Germans Trias i Pujol, Universitat Autònoma de Barcelona, Carretera del Canyet s/n, ES-08916 Badalona, Barcelona, Spain

Full list of author information is available at the end of the article
}

hypoalbuminemia, hyperlipidemia and edema, without an underlying etiology [1, 2]. The final diagnosis of glomerular diseases is based on renal biopsy findings and their correlation with clinical, laboratory and serological results. Moreover, renal biopsy is useful for determining the prognosis and for choosing the most appropriate treatment, although the invasiveness of this technique may lead to serious complications [3-5].

Anatomopathologic study combines conventional light microscopy, immunohistology and electron microscopy, and requires an adequate amount of tissue, with a sufficient number of glomeruli to evidence the lesion [6-8]. 
Light microscopy shows normal glomeruli in MCD and segmental scarring in some, but not all, glomeruli in FSGS. In both entities, electron microscopy typically demonstrates specific ultrastructural findings of diffuse effacement of podocytes' foot processes in the absence of electron-dense deposits $[9,10]$. Due to the focal nature of FSGS, it is complicated to identify this lesion if no affected glomeruli are sampled in the biopsy, and a misdiagnosis of these patients as MCD may occur [8]. The correct diagnosis is crucial to an effective treatment, as MCD is typically responsive to steroid therapy with excellent long-term prognosis, whereas FSGS is usually resistant to steroid therapy and has progressive glomerular filtration rate loss $[11,12]$. Consequently, the different therapy approach and the toxicity of steroids make it especially important to differentiate between these disorders.

During the last decades, major technological advances in the field of proteomics have greatly encouraged the search for diagnostic biomarkers of diseases in biological fluids, because extracellular proteins provide valuable information on the physiological state of the entire organism and of specific organs. For this purpose, twodimensional gel electrophoresis coupled with mass spectrometry (MS) is a commonly used approach. Recently, two-dimensional differential gel electrophoresis (2DDIGE) has emerged, in which various protein sources are fluorescently labeled, mixed, and run simultaneously on the same polyacrylamide gel. This methodology allow the separation and quantitative analysis of two or more different protein samples within the same gel, reducing gel to gel variation and overcoming the reproducibility and sensitivity limitations of the traditional two-dimensional gel electrophoresis [13].

Among the different biological fluids, urine has the advantage of being obtained easily and non-invasively, in large amounts, and at minimum cost. In addition, urine contains proteins from plasma and from the kidneys, reflecting both systemic and renal physiology. Several studies have been conducted to identify urinary biomarkers of kidney diseases [14-18].

In this study, the urinary proteome of a group of MCD and FSGS biopsy-diagnosed patients was compared aiming to find out candidate biomarkers capable to differentiate between these glomerular diseases.

\section{Methods}

\section{Patients}

In the period between January 2007 and December 2013, 49 patients biopsy-diagnosed of MCD $(n=24)$ and primary FSGS $(n=25)$ were included in this prospective study. Inclusion criteria were: i) Caucasian race, ii) $>18$ years old, iii) diagnosis achieved by renal biopsy during the initial nephrotic syndrome presentation and before starting any pharmacological therapy (steroids, immunosuppressant drugs, angiotensin converting enzyme inhibitors, angiotensin receptor blockers, etc.), iv) stable renal function (follow-up two years after diagnosis). Clinical or pathological features indicating a secondary cause such as autoimmune diseases, infections, cancer or exposure to nephrotoxic drugs were excluded.

Urine and blood samples were collected the same day of renal biopsy, prior to performing it. All samples were processed identically.

The Research Ethics Committee of the Germans Trias i Pujol Hospital approved the study protocol and all patients gave their written informed consent to participate.

\section{Study design}

MCD and FSGS patients were randomly subdivided into a training set (10 MCD, 11 FSGS) used to perform the 2D-DIGE analysis, and a validation set (14 MCD, 14 FSGS) used to validate the results.

\section{Renal biopsy}

Patients' histological diagnosis was achieved by a percutaneous renal biopsy.

Biopsies were performed using a Bard Monopty Disposable Core Biopsy Instrument (Bard Biopsy Systems, Tempe, AZ, USA) under ultrasound guidance and routinely processed for light microscopy, immunofluorescence, and electron microscopy examination according to established protocols and image analysis techniques. Light microscopy sections were stained hematoxylin and eosin, periodic acid Schiff, silver methenamine, Masson's trichrome and Congo red. Immunofluorescence was performed by incubating cryostat sections with polyclonal fluorescein isothiocyanateconjugated secondary antibodies against IgG, IgM, IgA, C3, C1q, C4, kappa, lambda and fibrinogen (Dako, Glostrup, Denmark). Tissue samples for electron microscopy were processed according to established techniques. Briefly, samples were fixed in $2 \%$ glutaraldehyde in phosphate buffer, post-fixed in 1\% osmium tetroxide and embedded in epon epoxy resin. Ultrathin sections were stained with uranyl acetate and lead citrate.

\section{Anthropometric and biochemical parameters}

Body surface area was calculated according to Dubois method [19]. Serum creatinine levels were determined using a modified Jaffe kinetic reaction (Roche Diagnostics, Basel, Switzerland). All patients underwent a complete haematological study that included serum glucose (hexokinase method) and serum protein (biuret method). Twenty-four hour proteinuria was measured spectrophotometrically on a Cobas u711 analyzer (Roche Diagnostics) according to the manufacturer's instructions. 


\section{Urine collection}

A first morning void was collected from all patients into a sterile plastic tube and immediately centrifuged at $2,100 \mathrm{~g}$ for $30 \mathrm{~min}$ at $4{ }^{\circ} \mathrm{C}$ to remove cell debris and particulate matter. The supernatant was recovered, adjusted to neutral $\mathrm{pH}$ with $1 \mathrm{M} \mathrm{NH}_{4} \mathrm{HCO}_{3}$, aliquoted, and immediately frozen at $-80{ }^{\circ} \mathrm{C}$ until further analysis.

\section{Sample labeling and two-dimensional gel electrophoresis}

The subset of samples from the training set were pooled together (10 MCD in sample \#1 and 11 FSGS in sample \#2), adding an equal amount of protein from each patient $(500 \mu \mathrm{g})$. Total protein concentration was assessed with the Quick Start Bradford protein assay kit (Bio-Rad Laboratories, Hercules, CA, USA) according to manufacturer instructions.

Pooled samples were centrifuged at $10,000 \mathrm{~g}$ for $10 \mathrm{~min}$ and the supernatant was precipitated by 2DECleanUp (GE Helthcare Life Science, Piscataway, NJ, USA). The pellets were resuspended in $100 \mu$ of lysis buffer (8 M Urea, 2.5\% CHAPS, 2\% ASB-14 and $30 \mathrm{mM}$ Tris- $\mathrm{HCl}, \mathrm{pH} 8.5)$.

To compare the urine proteomes of both glomerular entities, $75 \mu \mathrm{g}$ of sample \#1 and $75 \mu \mathrm{g}$ of sample \#2 were labeled with different CyDye fluorofors $(\mathrm{Cy} 2$ for a pool of both samples, Cy3 for sample \# 1 and Cy5 for sample \#2) before the two-dimensional polyacrylamide gel electrophoresis (2D-PAGE). Each sample was labeled with 8 pmol of CyDye per $\mu$ g of protein and incubated on ice for $30 \mathrm{~min}$ in the dark. The labelling reaction was quenched by adding $1 \mu \mathrm{l}$ of $10 \mathrm{mM}$ lysine and incubated on ice for $10 \mathrm{~min}$ in the dark, according to manufacturer's instructions (GE Healthcare Life Science).

2D-PAGE with immobilized $\mathrm{pH}$ gradient was carried out according to Görg et al. [20]. The labelled samples $\# 1$ and \#2 were mixed together and then run in the firstdimension by isoelectric focusing (IEF), using the cup- loading method, onto previously rehydrated $24 \mathrm{~cm}$ IPG drystrips (GE Healthcare Life Science) with immobilized linear 3-10 pH gradient. IEF was performed at $300 \mathrm{~V}$ for $1 \mathrm{~h}$, followed by 3 gradient steps $(1000 \mathrm{~V}$ for $30 \mathrm{~min}$, $5000 \mathrm{~V}$ for $80 \mathrm{~min}$, and $8000 \mathrm{~V}$ for $30 \mathrm{~min}$ ) and finally $8000 \mathrm{~V}$ for $2 \mathrm{~h}$. On completion of the IEF, the strips were equilibrated and proteins separated on the seconddimension on a $12 \%$ polyacrylamide gel. The electrophoresis was performed at $14{ }^{\circ} \mathrm{C}$ until the front of fast migrating ions reached the bottom of the gel. The analytical gels were run in triplicate.

Fluorescence images of the gels were acquired on a Typhoon 9400 scanner (GE Healthcare Life Science) at appropriate wavelengths for $\mathrm{Cy} 3$ and $\mathrm{Cy} 5$ dyes, and at a resolution of $100 \mu \mathrm{m}$. Digitalized images were evaluated using SameSpots v4.0 software (TotalLab Ltd., Newcastle, UK).

\section{Spot picking and mass spectrometric protein identification}

Preparatory 2D-PAGE gels were run to be visualized by colloidal Coomassie staining. Stained gels were scanned with Typhoon scanner and resulting images were matched and aligned with the previous $\mathrm{Cy} 3$ and $\mathrm{Cy} 5$ fluorescence images. Those spots whose protein abundance was increased or decreased more than 1.5-fold were listed for being identified by matrix-assisted laser desorption/ionization time of flight (MALDI-TOF) peptide mass fingerprinting. The spots of interest were excised from the polyacrylamide gel, destained, and digested with $30 \mathrm{ng}$ of sequencing grade trypsin (Promega, Madison, WI, USA) for $4 \mathrm{~h}$ at $37^{\circ} \mathrm{C}$. Peptides were eluted by centrifugation with $40 \mu \mathrm{l}$ of acetonitrile: $\mathrm{H}_{2} \mathrm{O}(1: 1)$ and $0.2 \%$ trifluoroacetic acid.

For MS analysis, the samples were prepared by mixing $0.5 \mu \mathrm{l}$ of sample with the same volume of a solution of alpha-cyano-4-hydroxycinnamic acid matrix $(10 \mathrm{mg} / \mathrm{ml}$

Table 1 Demographic and clinical characteristics of the study population

\begin{tabular}{|c|c|c|c|c|c|c|c|c|}
\hline & \multicolumn{3}{|l|}{ Training Set } & \multicolumn{3}{|l|}{ Validation Set } & \multicolumn{2}{|l|}{$P_{\mathrm{T}-\mathrm{V}}$} \\
\hline & MCD & FSGS & $P$ & MCD & FSGS & $P$ & MCD & FSGS \\
\hline No. of subjects & 10 & 11 & & 14 & 14 & & & \\
\hline Age (years) & $39.5(28.0-68.0)$ & $57.0(31.0-71.0)$ & 0.57 & $55.5(30.0-72.0)$ & $54.5(36.0-59.0)$ & 0.45 & 0.32 & 0.85 \\
\hline Female/male ratio & $3 / 7$ & $5 / 6$ & 0.47 & $6 / 8$ & $2 / 12$ & 0.09 & 0.52 & 0.08 \\
\hline Body mass index $\left(\mathrm{kg} / \mathrm{m}^{2}\right)$ & $27.3(21.9-33.8)$ & $25.5(24.0-26.6)$ & 0.68 & $29.4(24.2-30.6)$ & $26.3(25.1-28.4)$ & 0.63 & 0.76 & 0.41 \\
\hline Body surface area & $1.7(1.7-1.9)$ & $1.8(1.6-1.8)$ & 0.83 & $1.8(1.6-1.9)$ & $1.9(1.8-2.0)$ & 0.35 & 0.52 & 0.11 \\
\hline Serum glucose (mg/dl) & $91(81-101)$ & $88(83-97)$ & 0.89 & $84(81-94)$ & $94(87-97)$ & 0.19 & 0.44 & 0.67 \\
\hline Serum protein (g/dl) & $4.4(3.7-4.7)$ & $5.0(4.1-6.2)$ & 0.09 & $4.7(4.1-4.9)$ & $6.1(4.5-6.3)$ & 0.05 & 0.29 & 0.56 \\
\hline Serum creatinine (mg/dl) & $0.9(0.8-1.0)$ & $1.2(0.9-1.2)$ & 0.12 & $0.9(0.8-1.3)$ & $1.3(0.9-1.8)$ & 0.24 & 0.64 & 0.62 \\
\hline Proteinuria (g/24 h) & $10.6(2.3-12.2)$ & $3.5(2.5-7.4)$ & 0.29 & $9.7(5.9-15.0)$ & $3.4(1.7-4.5)$ & 0.004 & 0.52 & 0.64 \\
\hline
\end{tabular}

Data are shown as median (interquartile range)

Differences between groups were tested using the non-parametric Kruskall Wallis test. $P_{\mathrm{T}-\mathrm{v}}$ shows $P$ value between training and validation set. $P<0.05$ was considered significant 
in $30 \%$ acetonitrile, $60 \%$ water, and $0.1 \%$ trifluoroacetic acid) and were spotted onto a ground steel plate (Bruker Daltonics, Bremen, Germany) and allowed to air-dry. MS spectra were recorded in the positive ion mode on an ultrafleXtreme time-of-flight instrument (Bruker Daltonics). Ion acceleration was set to $25 \mathrm{kV}$. All mass spectra were externally calibrated using a standard peptide mixture (Bruker Daltonics).

Protein identifications were carried out by Mascot search engine (Matrix Science, Boston, MA, USA), against the NCBInr protein database with the following parameters: 3 maximum missed trypsin cleavages, cysteine carbamidomethylation and methionine oxidation as variable modifications and $50 \mathrm{ppm}$ tolerance.

\section{Enzyme-linked Immunosorbent assay (ELISA)}

The concentration of the proteins identified was assessed using commercially available ELISA kits (Additional file 1) according to manufacturer's instructions. Each sample was assayed in duplicate. Absorbance optical density values were read fluorometrically at $450 \mathrm{~nm}$ on a Varioskan Flash spectral scanning reader (Thermo

Table $\mathbf{2}$ List of proteins identified in urine from training set using peptide mass fingerprinting

\begin{tabular}{|c|c|c|c|c|c|c|c|c|c|c|c|}
\hline$\#$ Spot $^{a}$ & P-value & MCD & FSGS & Fold $^{b}$ & Trend $^{c}$ & Protein name & Gene name & $\begin{array}{l}\text { UniProt } \\
\text { accession no. }\end{array}$ & Seq. Cov. (\%) & $\begin{array}{l}\text { Matched } \\
\text { peptides }\end{array}$ & $\begin{array}{l}\text { MASCOT } \\
\text { Score }\end{array}$ \\
\hline 1,064 & 0.004 & 0.39 & 1.67 & 4.3 & Down & $\begin{array}{l}\text { Branched-chain-amino-acid } \\
\text { aminotransferase, mithocondrial }\end{array}$ & BCAT2 & 015382 & 19.9 & 5 & 42.4 \\
\hline 1,070 & 0.004 & 0.18 & 2.04 & 11.5 & Down & $\begin{array}{l}\text { Nuclear inhibitor of protein } \\
\text { phosphatase I }\end{array}$ & PPP1R8 & Q12972 & 28.2 & 7 & 48.4 \\
\hline \multirow[t]{3}{*}{1,334} & $<0.001$ & 1.79 & 0.44 & 4.1 & Up & Alpha-1-antitrypsin & SERPINA1 & P01009 & 21.3 & 6 & 44.6 \\
\hline & & & & & & Platelet-activating factor receptor & PTAFR & P25105 & 17.3 & 5 & 46.5 \\
\hline & & & & & & Cyclin-Y & CCNY & Q8ND76 & 32.6 & 7 & 49.8 \\
\hline 1,352 & $<0.001$ & 1.79 & 0.43 & 4.2 & Up & Alpha-1-antitrypsin & SERPINA1 & P01009 & 49.3 & 13 & 51.7 \\
\hline \multirow[t]{2}{*}{1,354} & $<0.001$ & 1.77 & 0.40 & 4.5 & Up & Alpha-1-antitrypsin & SERPINA1 & P01009 & 49.3 & 18 & 86.3 \\
\hline & & & & & & $\begin{array}{l}\text { Transmembrane channel-like } \\
\text { protein } 1\end{array}$ & TMC1 & Q8TDI8 & 23.9 & 15 & 33.4 \\
\hline 1,356 & $<0.001$ & 1.85 & 0.38 & 4.8 & Up & $\begin{array}{l}\text { Transcription elongation factor } 1 \\
\text { homolog }\end{array}$ & ELOF1 & P60002 & 51.8 & 7 & 36.2 \\
\hline 1,363 & $<0.001$ & 1.51 & 0.59 & 2.6 & Up & Transferrin & TF & P02787 & 24.5 & 12 & 64.9 \\
\hline \multirow[t]{2}{*}{1,392} & 0.01 & 0.31 & 1.57 & 5.1 & Down & Serum albumin & ALB & P02768 & 28.1 & 16 & 58.6 \\
\hline & & & & & & $\begin{array}{l}\text { Leucine-rich repeat-containing } \\
\text { protein } \mathrm{C} 10 \text { orf } 11\end{array}$ & c10orf11 & $\mathrm{Q} 9 \mathrm{H} 218$ & 36.9 & 6 & 41.6 \\
\hline 1,400 & 0.005 & 2.18 & 0.38 & 5.7 & Up & Serum albumin & ALB & P02768 & 39.4 & 21 & 85.1 \\
\hline 1,408 & 0.006 & 2.17 & 0.49 & 4.4 & Up & Serum albumin & ALB & P02768 & 53.2 & 31 & 92.1 \\
\hline \multirow[t]{2}{*}{1,458} & 0.002 & 0.28 & 1.69 & 6.1 & Down & $\begin{array}{l}\text { PEST proteolytic signal-containing } \\
\text { nuclear protein }\end{array}$ & PCNP & Q8WW12 & 51.7 & 5 & 38.6 \\
\hline & & & & & & $\begin{array}{l}\text { Branched-chain -amino-acid } \\
\text { aminotransferase, mithocondrial }\end{array}$ & BCAT2 & 015382 & 19.9 & 5 & 42.4 \\
\hline \multirow[t]{2}{*}{1,460} & $<0.001$ & 0.25 & 1.72 & 7 & Down & $\begin{array}{l}\text { Leucine-rich repeat-containing } \\
\text { protein } \mathrm{C} 10 \text { orf } 11\end{array}$ & c10orf11 & Q9H2l8 & 36 & 9 & 32.7 \\
\hline & & & & & & Calretinin & CALB2 & P22676 & 32.1 & 7 & 27.9 \\
\hline \multirow[t]{3}{*}{1,468} & $<0.001$ & 2.22 & 0.71 & 3.1 & Up & Serum albumin & ALB & P02768 & 24.8 & 21 & 80.2 \\
\hline & & & & & & $\begin{array}{l}39 S \text { Ribosomal protein L17, } \\
\text { mithocondrial }\end{array}$ & MRPL17 & Q9NRX2 & 62.9 & 9 & 40 \\
\hline & & & & & & Humanin-like protein 6 & HN6 & P0CJ73 & 100 & 7 & 64.1 \\
\hline \multirow[t]{2}{*}{1,469} & $<0.001$ & 2.98 & 0.68 & 4.4 & Up & Serum albumin & ALB & P02768 & 28.2 & 25 & 56.6 \\
\hline & & & & & & Histatin-3 & HTN3 & P15516 & 68.6 & 4 & 36.7 \\
\hline 7,740 & $<0.001$ & 1.27 & 0.49 & 2.6 & Up & Zinc-alpha-2-glycoprotein & AZGP1 & P25311 & & & 155 \\
\hline 7,810 & $<0.001$ & 1.27 & 0.49 & 2.6 & Up & Zinc-alpha-2-glycoprotein & AZGP1 & P25311 & 28.9 & 10 & 61.9 \\
\hline
\end{tabular}

${ }^{a}$ Spot number generated by SameSpots image analysis software, referencing the spots shown on Additional file 2

${ }^{\mathrm{b}}$ Ratio of protein expression between MCD and FSGS

'Up: up-regulated in MCD compared to FSGS; Down: down-regulated in MCD compared to FSGS

${ }^{d}$ Accession number from NCBInr database 
Fisher Scientific, Vantaa, Finland). The measured concentrations were assessed with the SkanIt Software for Varioskan Flash (version 2.4.1) by extrapolation from a standard curve generated from the standards supplied in the kits.

\section{Statistical analyses}

The first step was performed using univariate and bivariate analyses. For continuous variables, expressed as median (interquartile range), groups were compared using the non-parametric Kruskal-Wallis test. For categorical variables, differences among groups were tested using Likelihood Ratio Chi-Square statistic.

A decision tree [21] was performed to obtain the set of the most discriminative proteins between MCD and FSGS patients. Ten 5-fold cross-validations were performed aiming to validate the decision tree. In addition, for the validation of the decision tree analysis, the corresponding area under the ROC curve (AUC) was calculated.

Statistical analyses were performed with the SAS software v9.3 (SAS Institute Inc., Cary, NC, USA). Significance level was fixed at 0.05 .

\section{Results}

Demographical and clinical data of patients are presented in Table 1.

Renal biopsies contained $22.36 \pm 11.50$ glomeruli.

\section{D-DIGE MS}

A total of 394 matched protein spots were detected in 2D-DIGE images (Additional file 2). A total of 242 spots showed a differential abundance when comparing MCD and FSGS (ANOVA, $P<0.05$ ); $57.4 \%$ and $42.6 \%$ were up-regulated in MCD and FSGS, respectively.

Differentially abundant protein spots (with averagefold change $>2$ and $P<0.01$ ) were targeted for MS analysis. The protein identification gave a total of 25 confident identifications, representing 16 proteins. Eleven of these proteins were up-regulated in MCD patients and 5 were up-regulated in FSGS patients. Table 2 shows the list of the identified proteins; in cases where multiple identifications were made from the same spot, all proteins are reported.

\section{Validation by ELISA}

The results of the validation are shown on Table 3 and Fig. 1.

Three DIGE spots, up-regulated in MCD, were identified as alpha-1-antitrypsin (AAT). The concentration of this protein was significantly higher in the urine of $\mathrm{MCD}$ patients.

The identification of the DIGE spot \#1,334 resulted in 2 proteins, platelet-activating factor receptor (PTAFR) and cyclin-Y, in addition to AAT. By ELISA we found
Table 3 Validation results

\begin{tabular}{lllll}
\hline & & $\mathrm{N}$ & Urine concentration & $P$ \\
\hline AAT & MCD & $13 / 14$ & $193.5(102.49-580.0) \mu \mathrm{g} / \mathrm{ml}$ & 0.002 \\
& FSGS & $14 / 14$ & $20.93(10.45-101.65) \mu \mathrm{g} / \mathrm{ml}$ & \\
TF & MCD & $12 / 14$ & $653.63(241.27-1,348.38) \mu \mathrm{g} / \mathrm{ml}$ & 0.002 \\
& FSGS & $14 / 14$ & $129.96(55.41-267.10) \mu \mathrm{g} / \mathrm{ml}$ & \\
HTN-3 & MCD & $5 / 14$ & $0.35(0.32-0.48) \mu \mathrm{g} / \mathrm{ml}$ & 0.03 \\
& FSGS & $3 / 14$ & $0.22(0.17-0.23) \mu \mathrm{g} / \mathrm{ml}$ & \\
MRPL17 & MCD & $12 / 14$ & $242.98(174.25-534.75) \mathrm{pg} / \mathrm{ml}$ & 0.001 \\
& FSGS & $14 / 14$ & $111.86(74.90-154.78) \mathrm{pg} / \mathrm{ml}$ & \\
PCNP & MCD & $14 / 14$ & $441.67(152.50-503.10) \mathrm{pg} / \mathrm{ml}$ & 0.72 \\
& FSGS & $12 / 14$ & $348.55(216.25-437.70) \mathrm{pg} / \mathrm{ml}$ & \\
CALB2 & MCD & $14 / 14$ & $3.52(2.88-4.40) \mathrm{pg} / \mathrm{ml}$ & 0.002 \\
& FSGS & $14 / 14$ & $6.98(4.29-8.65) \mathrm{pg} / \mathrm{ml}$ & \\
CCNY & MCD & $12 / 14$ & $87.60(83.40-91.15) \mathrm{pg} / \mathrm{ml}$ & 0.71 \\
& FSGS & $12 / 14$ & $87.70(84.30-102.2) \mathrm{pg} / \mathrm{ml}$ & \\
PTAFR & MCD & $5 / 14$ & $0.84(0.46-0.98) \mathrm{ng} / \mathrm{ml}$ & 0.25 \\
& FSGS & $2 / 14$ & $0.51(0.36-0.66) \mathrm{ng} / \mathrm{ml}$ & \\
\hline
\end{tabular}

$\mathrm{N}$ represents the number of urine samples in which the proteins were detected by ELISA

the presence of these proteins in the urine of some patients of the validation set, but no differences were observed when comparing MCD and FSGS.

One DIGE, up-regulated in MCD, was identified as transferrin (TF). By ELISA, we found a higher concentration of this protein in the urine of MCD.

Another spot up-regulated in MCD was identified as Histatin-3 (HTN). This protein was only detected by ELISA in 8 patients, with higher concentration in those diagnosed MCD.

Another spot up-regulated in MCD was identified as 39 S ribosomal protein L17, mitochondrial (MRPL17). The concentration of this protein was higher in the urine of MCD patients.

One DIGE up-regulated in FSGS was identified as calretinin (CALB2). This protein was in a higher concentration in urine of FSGS patients.

The spot \#1,458, up-regulated in MCD patients, was identified as PEST proteolytic signal-containing nuclear protein. By ELISA, no differences were found.

The rest of proteins identified were not detected by ELISA in the urine of patients from the validation set.

\section{Decision tree analysis}

In the first step for building the decision tree, CALB2 was used for classifying patients. Hence, 2 groups were obtained: 19 patients (14 MCD, 5 FSGS) with levels of CALB2 $<6.4 \mathrm{ng} / \mathrm{ml}$ and 9 patients (9 FSGS) with levels of CALB2 $>=6.4 \mathrm{ng} / \mathrm{ml}$. In the second step, for the 


\section{DIGE \\ Training Set \\ ELISA \\ Validation Set}

\section{Spot MCD FSGS}

$\# 1,334$
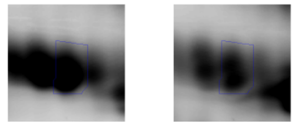

$\# 1,352$
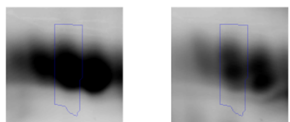

$\# 1,354$
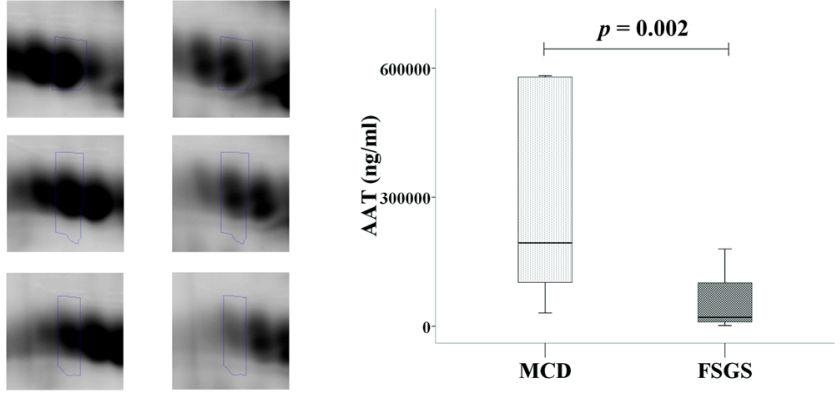

$\# 1,363$
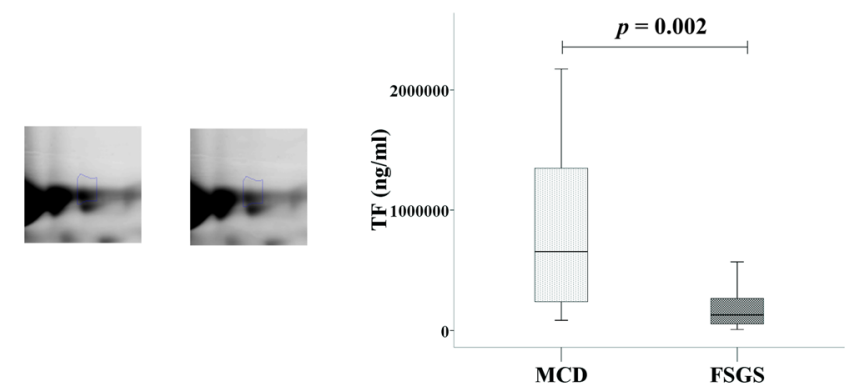

$\# 1,469$
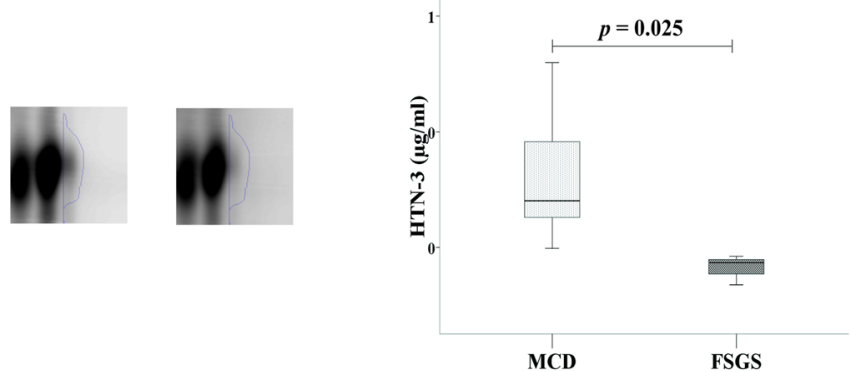

MCD

FSGS

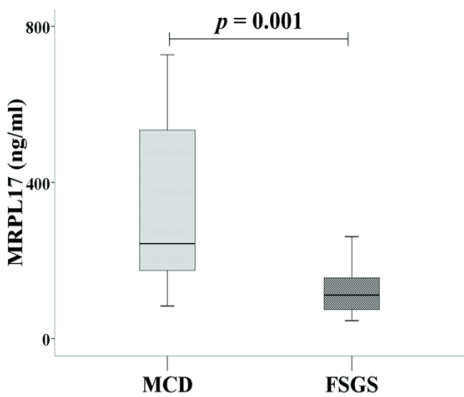

Fig. 1 Selection of DIGE spots and validation by ELISA

group who had levels of CALB2 $<6.4 \mathrm{ng} / \mathrm{ml}$, the best partition was using the value of MRPL17 $>=139.29 \mathrm{pg} /$ $\mathrm{ml}$. To conclude, a final partition was defined by the detection of HTN, in the group who had levels of CALB2 $<6.4 \mathrm{ng} / \mathrm{ml}$ and MRPL17 $<139.29 \mathrm{pg} / \mathrm{ml}$.
Accordingly, 4 groups of patients were obtained (Fig. 2). Group 1 included 9 patients, all of them FSGS with levels of CALB2 $>=6.4 \mathrm{ng} / \mathrm{ml}$; Group 2 included 11 patients (10 MCD, 1 FSGS) with levels of CALB2 < $6.4 \mathrm{ng} / \mathrm{ml}$ and MRPL17 > = $139.29 \mathrm{pg} / \mathrm{ml}$. Moreover, 


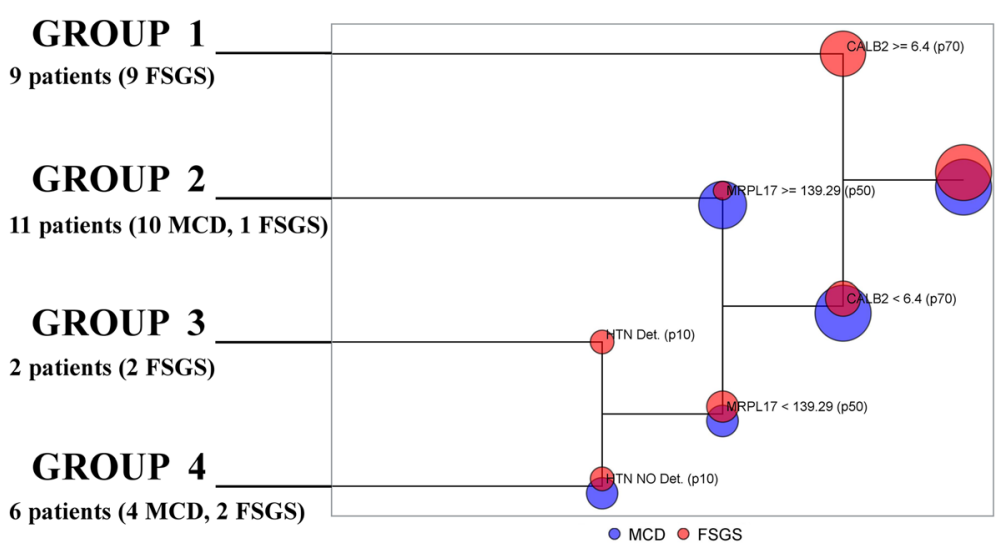

Fig. 2 Decision tree analysis

these patients showed high levels of AAT, TF, HTN and PTAFR; Group 3 included 2 FSGS patients with levels of CALB2 $<6.4 \mathrm{ng} / \mathrm{ml}$, levels of MRPL17 < $139.29 \mathrm{pg} / \mathrm{ml}$ and detection of HTN; Group 4 included 6 patients (4 MCD, 2 FSGS) with levels of CALB2 < $6.4 \mathrm{ng} / \mathrm{ml}$, levels of MRPL17 $<139.29 \mathrm{pg} / \mathrm{ml}$ and no detection of HTN. Groups 2 and 4 were mainly composed of MCD patients, and Groups 1 and 3 included only FSGS patients. Therefore, the predicted-MCD patients were those in Groups 2 and 4, and the predicted-FSGS patients were those in Groups 1 and 3. All MCD patients were classified as predictedMCD, while $78.6 \%$ of FSGS were correctly predicted.

From the validation analysis, the AUC was 0.89 and 95\% Confidence Interval $=[0.78,1]$.

\section{Discussion}

We included a highly selected group of patients with clinical and histological diagnosis of MCD and FSGS. The diagnosis of FSGS is established by the finding of at least a single abnormal glomerulus and it has been stated that the probability of misdiagnosis is statistically relevant when fewer than eight glomeruli are found in biopsy samples [8]. In our study, all tissue samples contained more than eight glomeruli. Moreover, we can state that all patients were correctly classified, as those diagnosed MCD achieved a complete remission, without any relapse for at least two years.

In recent years, several research groups have proposed different urinary biomarkers to differentiate between these glomerular diseases, such as CD80 and TGF $\beta[22,23]$, but there is not enough evidence to use them in clinical practice. These candidate biomarkers need further validation and in a larger cohort.

Of our results, we consider highly interesting the finding of a set of proteins whose concentration in urine was different between these glomerular diseases. With some of these proteins, named calretinin, histatin- 3 and
$39 \mathrm{~S}$ ribosomal protein L17, we built a decision tree capable to predict patient's pathology.

These results were obtained after conducting a proteomic study. Beside direct analysis of renal tissue, urinary proteome study has potential value in the noneinvasive diagnosis of kidney diseases diagnosis. We focused on MCD and FSGS in which the histological study may be similar and lead to an erroneous diagnosis. Consequently, our results may be useful to clinicians to confirm the diagnosis and thereby avoid unnecessary or inadequate treatments.

The comparison of the urinary proteome of MCD and FSGS patients was achieved by 2D-DIGE, resulting in 16 proteins as possible biomarkers. Various proteins were identified in different spots, and numerous spots contained more than one protein, making it difficult to attribute abundance changes to a specific protein. For that reason, the results obtained by 2D-DIGE were validated by independent ELISA analyses.

Various DIGE spots that were up-regulated in MCD were identified as AAT. By ELISA we corroborated that this protein was in a higher concentration in the urine of $\mathrm{MCD}$ patients. AAT is a $52-\mathrm{kDa}$ glycoprotein and the most abundant circulating serine protease inhibitor of a broad range of proteases, mainly against neutrophil elastase. AAT protects tissues from enzymes released from cells when they are injured and inflamed. Other functions of AAT have been suggested, such as modulating immunity, inflammation and apoptosis [24, 25]. AAT is mainly synthesized in the liver and to a lesser extent by a variety of extra-hepatic tissues, such as renal tubular epithelial cells. Several studies have revealed that AAT protects the kidney by anti-apoptotic and anti-inflammatory routes in renal ischemic/reperfusion injury and it has been proposed as a biomarker for acute kidney injury (AKI) [26-28]. Since AKI can be due to a glomerular injury, we paid attention at the renal function of our patients and observed that there were no differences in serum creatinine levels between MCD and FSGS. 
Other studies have described a high presence of AAT in the urine of patients with nephrotic syndrome, and a practical absence in the urine of healthy subjects [29, 30]. In agreement, in a previous study, by analyzing the urinary peptidome, we found one peptide, identified as AAT, that showed a higher intensity in MCD compared with FSGS [31].

The present study also revealed higher levels of TF in MCD. Urinary TF results from abnormal permeability of the glomerular basement membrane, and it has been suggested to be a marker for early stages of glomerular diseases. Increased urinary TF excretion has been suggested to precede the development of microalbuminuria in glomerular diseases [32]. Other studies have found that urinary TF may predict the severity of mesangial cellularity and glomerulosclerosis in the early stages of glomerular diseases [33].

MRPL17 is a protein encoded by nuclear genes and helps in protein synthesis within the mitochondrion. To our knowledge, there are no studies relating this protein with kidney diseases.

We identified CALB2 as another possible candidate biomarker capable of differentiating MCD from FSGS. CALB2, a $29 \mathrm{kDa}$ calcium-binding protein belonging to the troponin $\mathrm{C}$ superfamily, is predominantly expressed in specific neurons of the central and peripheral nervous system. This protein is involved in diverse cellular functions including intracellular calcium buffering, messenger targeting, and the modulation of neuronal excitability. CALB2 has been proposed as a diagnostic marker for some human diseases, including Hirschsprung disease and some cancers, such as mesothelioma and lung tumours [34-36].

\section{Conclusions}

In conclusion, given the difficulty in differentiating, in some cases, between MCD and FSGS by evaluation of renal biopsies, it becomes necessary to search for diagnostic biomarkers. In this study, we built a decision tree which seems a good tool for predicting patient's pathology when there are doubts if it is MCD or FSGS, although future efforts must be made to include more patients and to evaluate its effectiveness.

\section{Additional files}

Additional file 1: (Table) List of commercially available ELISA kits used to validate proteins identified by peptide mass fingerprinting. (PDF 7 kb)

Additional file 2: (Figure) Image of a preparatory 2D-PAGE gel used to pick spots. (JPG $1318 \mathrm{~kb}$ )

\section{Abbreviations}

2D-DIGE: Two-dimensional differential gel electrophoresis; 2D-PAGE: Twodimensional polyacrylamide gel electrophoresis; AAT: Alpha-1-antitrypsin; AKI: Acute kidney injury; AUC: Area under the ROC curve; CALB2: Calretinin;
ELISA: Enzyme-linked immunosorbent assay; FSGS: Focal segmental glomerulosclerosis; HTN: Histatin-3; IEF: Isoelectric focusing; MALDITOF: Matrix-assisted laser desorption/ionization time of flight; MCD: minimal change disease; MRPL17: 395 ribosomal protein L17, mitochondrial; MS: Mass spectrometry; PTAF: Platelet-activating factor receptor; TF: Transferrin

\section{Acknowledgements}

2D-DIGE and MS analyses were carried out in the Proteomics facility from UAB, a member of the ProteoRed-ISCIII network.

\section{Funding}

This work was supported by grants from the Fondo de Investigación Sanitaria and the Instituto de Salud Carlos III (PI13/00895 and ISCIII-RETICS REDinREN RD06/0016) from Spain. The funders had no role in study design, data collection and analysis, decision to publish, or preparation of the manuscript.

\section{Availability of data and materials}

The datasets analyzed during the current study available from the corresponding author on reasonable request.

\section{Authors' contributions}

VP and RR conceived and designed the study. DL, MI, JB and RR carried out the histological study of renal biopsies. VP and MI carried out the collection of samples. VP performed laboratory experiments. VP, DL, JB and RR analyzed data. VP, EB and AE performed the statistical analyses. VP drafted the manuscript and. $D L, E B, M I, A E, J B$ and $R R$ revised it critically for important intellectual content.

All authors gave their final approval of the manuscript to be published and accepted accountability for the overall work by ensuring that questions pertaining to the accuracy or integrity of any portion of the work were appropriately investigated and resolved.

\section{Competing interests}

The authors declare that they have no competing interests.

\section{Consent for publication}

Not applicable.

\section{Ethics approval and consent to participate}

The Research Ethics Committee of the Germans Trias i Pujol Hospital (CEl HUGTiP) approved the study protocol and all patients gave their written informed consent to participate.

\section{Author details \\ ${ }^{1}$ Laboratory of Experimental Nephrology, Institut d'Investigació en Ciències de la Salut Germans Trias i Pujol, Universitat Autònoma de Barcelona, Badalona, Spain. ${ }^{2}$ Department of Nephrology, Hospital Universitari Germans Trias i Pujol, Universitat Autònoma de Barcelona, Carretera del Canyet s/n, ES-08916 Badalona, Barcelona, Spain. ${ }^{3}$ Department of Pathology, Hospital Universitari Germans Trias i Pujol, Universitat Autònoma de Barcelona, Badalona, Spain. ${ }^{4}$ Applied Statistics Service, Universitat Autònoma de Barcelona, Bellaterra, Spain. ${ }^{5}$ Department of Medicine, Universitat Autònoma de Barcelona, Badalona, Spain.}

Received: 20 September 2016 Accepted: 16 January 2017

Published online: 03 February 2017

\section{References}

1. Braden GL, Mulhern JG, O'Shea MH, Nash SV, Ucci AA, Germain MJ. Changing incidence of glomerular diseases in adults. Am J Kidney Dis Off J Natl Kidney Found. 2000;35:878-83.

2. McGrogan A, Franssen CFM, de Vries CS. The incidence of primary glomerulonephritis worldwide: a systematic review of the literature. Nephro Dial Transplant. 2011;26:414-30.

3. Corapi KM, Chen JLT, Balk EM, Gordon CE. Bleeding complications of native kidney biopsy: a systematic review and meta-analysis. Am. J. Kidney Dis. Off. J Natl Kidney Found. 2012;60:62-73.

4. Eiro M, Katoh T, Watanabe T. Risk factors for bleeding complications in percutaneous renal biopsy. Clin Exp Nephrol. 2005;9:40-5.

5. Madaio MP. Renal biopsy. Kidney Int. 1990;38:529-43. 
6. Corwin HL, Schwartz MM, Lewis EJ. The importance of sample size in the interpretation of the renal biopsy. Am J Nephrol. 1988;8:85-9.

7. Fogo AB. Approach to renal biopsy. Am J Kidney Dis Off J Natl Kidney Found. 2003;42:826-36.

8. Fuiano G, Comi N, Magri P, Sepe V, Balletta MM, Esposito C, et al. Serial morphometric analysis of sclerotic lesions in primary "focal" segmental glomerulosclerosis. J Am Soc Nephrol JASN. 1996;7:49-55.

9. Fogo AB, Lusco MA, Najafian B, Alpers CE. AJKD Atlas of Renal Pathology: Focal Segmental Glomerulosclerosis. Am J Kidney Dis Off J Natl Kidney Found. 2015;66:e1-2

10. Fogo AB, Lusco MA, Najafian B, Alpers CE. AJKD Atlas of Rena Pathology: Minimal Change Disease. Am J Kidney Dis Off J Natl Kidney Found. 2015;66:376-7.

11. Mak SK, Short CD, Mallick NP. Long-term outcome of adult-onset minimalchange nephropathy. Nephrol Dial Transplant Off Publ Eur Dial Transpl Assoc - Eur Ren Assoc. 1996;11:2192-201.

12. Waldman M, Crew RJ, Valeri A, Busch J, Stokes B, Markowitz G, et al. Adult minimal-change disease: clinical characteristics, treatment, and outcomes. Clin J Am Soc Nephrol CJASN. 2007:2:445-53.

13. Timms JF, Cramer R. Difference gel electrophoresis. Proteomics. 2008:8:4886-97.

14. Lapolla A, Seraglia R, Molin L, Williams K, Cosma C, Reitano R, et al. Low molecular weight proteins in urines from healthy subjects as well as diabetic, nephropathic and diabetic-nephropathic patients: a MALDI study. J Mass Spectrom JMS. 2009;44:419-25.

15. Navarro-Muñoz $M$, Ibernon $M$, Bonet J, Pérez $V$, Pastor $M C$, Bayés $B$, et al. Uromodulin and a(1)-antitrypsin urinary peptide analysis to differentiate glomerular kidney diseases. Kidney Blood Press Res. 2012;35:314-25.

16. O'Seaghdha CM, Hwang S-J, Larson MG, Meigs JB, Vasan RS, Fox CS. Analysis of a urinary biomarker panel for incident kidney disease and clinical outcomes. J Am Soc Nephrol JASN. 2013;24:1880-8.

17. Jiang $S$, Wang Y, Liu Z. The application of urinary proteomics for the detection of biomarkers of kidney diseases. Adv Exp Med Biol. 2015;845: 151-65.

18. Øvrehus MA, Zürbig P, Vikse BE, Hallan SI. Urinary proteomics in chronic kidney disease: diagnosis and risk of progression beyond albuminuria. Clin Proteomics. 2015;12:21.

19. Du Bois D, Du Bois EF. A formula to estimate the approximate surface area if height and weight be known. 1916. Nutr Burbank Los Angel Cty Calif. 1989;5:303-311-313

20. Görg A, Weiss W, Dunn MJ. Current two-dimensional electrophoresis technology for proteomics. Proteomics. 2004;4:3665-85.

21. Hastie T, Tibshirani R, Friedman JH: The Elements of Statistical Learning: Data Mining, Inference, and Prediction. Springer. 2001

22. Garin EH, Mu W, Arthur JM, Rivard CJ, Araya CE, Shimada M, et al. Urinary CD80 is elevated in minimal change disease but not in focal segmental glomerulosclerosis. Kidney Int. 2010;78:296-302.

23. Woroniecki RP, Shatat IF, Supe K, Du Z, Kaskel FJ. Urinary cytokines and steroid responsiveness in idiopathic nephrotic syndrome of childhood. Am J Nephrol. 2008:28:83-90.

24. Hunt JM, Tuder R. Alpha 1 anti-trypsin: one protein, many functions. Curr Mol Med. 2012;12:827-35.

25. Pott GB, Chan ED, Dinarello CA, Shapiro L. Alpha-1-antitrypsin is an endogenous inhibitor of proinflammatory cytokine production in whole blood. J Leukoc Biol. 2009;85:886-95.

26. Daemen MA, Heemskerk VH, van't Veer C, Denecker G, Wolfs TG, Vandenabeele $P$, et al. Functional protection by acute phase proteins alpha(1)-acid glycoprotein and alpha(1)-antitrypsin against ischemia/ reperfusion injury by preventing apoptosis and inflammation. Circulation. 2000;102:1420-6.

27. Metzger J, Kirsch T, Schiffer E, Ulger P, Mentes E, Brand K, et al. Urinary excretion of twenty peptides forms an early and accurate diagnostic pattern of acute kidney injury. Kidney Int. 2010;78:1252-62.

28. Zager RA, Johnson ACM, Frostad KB. Rapid renal alpha-1 antitrypsin gene induction in experimental and clinical acute kidney injury. PLoS One. 2014;9:e98380

29. Candiano G, Musante L, Bruschi M, Petretto A, Santucci L, Del Boccio P, et al. Repetitive fragmentation products of albumin and alpha1-antitrypsin in glomerular diseases associated with nephrotic syndrome. J Am Soc Nephrol JASN. 2006;17:3139-48.

30. Magistroni R, Ligabue G, Lupo V, Furci L, Leonelli M, Manganelli L, et al. Proteomic analysis of urine from proteinuric patients shows a proteolitic activity directed against albumin. Nephrol Dial Transplant Off Publ Eur Dial Transpl Assoc - Eur Ren Assoc. 2009;24:1672-81.

31. Pérez V, Ibernón M, López D, Pastor MC, Navarro M, Navarro-Muñoz M, et al. Urinary peptide profiling to differentiate between minimal change disease and focal segmental glomerulosclerosis. PLoS One. 2014;9:e87731.

32. Bernard AM, Amor AA, Goemaere-Vanneste J, Antoine JL, Lauwerys RR, Lambert $A$, et al. Microtransferrinuria is a more sensitive indicator of early glomerular damage in diabetes than microalbuminuria. Clin Chem. 1988;34:1920-1.

33. Li Y, Wang J, Zhu X, Feng Q, Li X, Feng X. Urinary protein markers predict the severity of renal histological lesions in children with mesangial proliferative glomerulonephritis. BMC Nephrol. 2012;13:29.

34. Marchevsky AM. Application of immunohistochemistry to the diagnosis of malignant mesothelioma. Arch Pathol Lab Med. 2008;132:397-401.

35. Saydan N, Salicio V, Cappelli-Gotzos B, Gotzos V. Expression of calretinin in human mesothelioma cell lines and cell cycle analysis by flow cytometry. Anticancer Res. 2001;21:181-8.

36. Małdyk J, Rybczyńska J, Piotrowski D, Kozielski R. Evaluation of calretinin immunohistochemistry as an additional tool in confirming the diagnosis of Hirschsprung disease. Pol J Pathol Off J Pol Soc Pathol. 2014;65:34-9.

\section{Submit your next manuscript to BioMed Central and we will help you at every step:}

- We accept pre-submission inquiries

- Our selector tool helps you to find the most relevant journal

- We provide round the clock customer support

- Convenient online submission

- Thorough peer review

- Inclusion in PubMed and all major indexing services

- Maximum visibility for your research

Submit your manuscript at www.biomedcentral.com/submit
) Biomed Central 